\title{
$2014 \mathrm{M} R \mathrm{R}$ FALL MEETING \& EXHIBIT
}

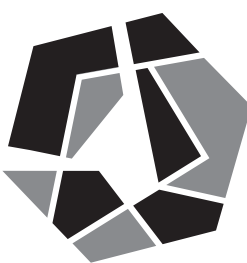

SYMPOSIA

\section{Preregistration Deadline-November 14, 2014}

\section{BIOMATERIALS AND SOFT MIATERIALS}

A Organic Bioelectronics

B Multifunctional Polymeric and Hybrid Materials

C Medical Applications of Noble Metal Nanoparticles (NMNPs)

D Materials and Concepts for Biomedical Sensing

E Hard-Soft Interfaces in Biological and Bioinspired MaterialsBridging the Gap between Theory and Experiment

$F \quad$ Reverse Engineering of Bioinspired Nanomaterials

G Plasma Processing and Diagnostics for Life Sciences

H Micro/Nano Engineering and Devices for Molecular and Cellular Manipulation, Stimulation and Analysis

I Emerging 1D and 2D Nanomaterials in Health Care

\section{ELECTRONICS AND PHOTONICS}

$\mathrm{J} \quad$ Emerging Non-Graphene 2D Atomic Layers and van der Waals Solids

K Graphene and Graphene Nanocomposites

L Optical Metamaterials and Novel Optical Phenomena Based on Nanofabricated Structures

M Materials and Technology for Nonvolatile Memories

$\mathrm{N} \quad$ Frontiers in Complex Oxides

0 Oxide Semiconductors

$P \quad$ Hybrid Oxide/Organic Interfaces in Organic Electronics

Q Fundamentals of Organic SemiconductorsSynthesis, Morphology, Devices and Theory

R Diamond Electronics and Biotechnology-Fundamentals to Applications

\section{ENERGY AND SUSTAINABILITY}

S Advances in Materials Science, Processing and Engineering for Fuel Cells and Electrolyzers

$\mathrm{T} \quad$ Wide-Bandgap Materials for Solid-State Lighting and Power Electronics

U Organic Photovoltaics-Fundamentals, Materials and Devices

V Sustainable Solar-Energy Conversion Using Earth-Abundant Materials

W Perovskite-Based and Related Novel Material Solar Cells

Y Technologies for Grid-Scale Energy Storage

Z Materials Challenges for Energy Storage across Multiple Scales

AA Synthesis, Processing and Mechanical Properties of Functional Hexagonal Materials for Energy Applications

BB Molecular, Polymer and Hybrid Materials for Thermoelectrics

CC Advanced Materials and Devices for Thermoelectric Energy Conversion

DD Materials for Advanced Nuclear Technologies

EE Scientific Basis for Nuclear Waste Management XXXVIII

FF Materials as Tools for Sustainability
NANOMATERIALS AND SYNTHESIS

GG Nanomaterials for Harsh Environment Sensors and Related Electronic and Structural ComponentsDesign, Synthesis, Characterization and Utilization

$\mathrm{HH}$ Flame and High-Temperature Synthesis of Functional NanomaterialsFundamentals and Applications

II Semiconductor Nanocrystals, Plasmonic Metal Nanoparticles and Metal-Hybrid Structures

JJ 3D Mesoscale ArchitecturesSynthesis, Assembly, Properties and Applications

KK Directed Self-Assembly for Nanopatterning

LL Semiconductor Nanowires-Growth, Physics, Devices, and Applications

THEORY, CHARACTERIZATION AND MODELING

MM Carbon Nanotubes-Synthesis, Properties, Functionalization and Applications

NN Mathematical and Computational Aspects of Materials Science

00 In Situ Characterization of Dynamic Processes during Materials Synthesis and Transformation

PP Advances in Scanning Probe Microscopy for Multimodal Imaging at the Nanoscale

QQ Advances in Nanoscale Subsurface, Chemical and Time-Resolved Studies of Soft Matter

RR Scaling Effects in PlasticitySynergy between Simulations and Experiments

SS Informatics and Genomics for Materials Development

TT Advanced Materials Exploration with Neutrons and X-RaysThe State-of-the-Art in the International Year of Crystallography

\section{GENERAL}

UU Structure-Property Relations in Amorphous Solids

VV Recent Advances in Reactive Materials

WW Defects and Radiation Effects in Advanced Materials

$X X$ Bridging Scales in Heterogeneous Materials

YY Advanced Structural and Functional Intermetallic-Based Alloys

ZZ Hierarchical, High-Rate, Hybrid and Roll-to-Roll Manufacturing

AAA Undergraduate Research in Materials Science-Impacts and Benefits

\section{Meeting Chairs}

Husam N. Alshareef King Abdullah University of Science and Technology Amit Goyal Oak Ridge National Laboratory

Gerardo Morell University of Puerto Rico

José A. Varela University of São Paulo State - UNESP

In Kyeong Yoo Samsung Advanced Institute of Technology
M $\mathbf{R}$ S MATERIALS RESEARCH SOCIETY

506 Keystone Drive • Warrendale, PA 15086-7573

Tel 724.779 .3003 • Fax 724.779 .8313

info@mrs.org・www.mrs.org
Don't Miss This Future MRS Meeting! 2015 MRS Spring Meeting \& Exhibit April 6-10, 2015

Moscone West \& San Francisco Marriott Marquis San Francisco, California 


\title{
MATERIALS RESEARCH SOCIETY ${ }^{\circledR}$
}

\section{Board of Directors Officers}

Tia Benson Tolle, President

Orlando Auciello, Immediate Past President

Oliver Kraft, Vice President

Sean J. Hearne, Secretary

Michael R. Fitzsimmons, Treasurer

Todd M. Osman, Executive Director

\author{
Directors \\ Shenda M. Baker \\ Alexandra Boltasseva \\ C. Jeffrey Brinker \\ David Cahen \\ Stephen J. Eglash \\ Chang-Beom Eom \\ Susan Ermer \\ Eric Garfunkel
}

\author{
Sossina M. Haile \\ Andrea M. Hodge \\ Hideo Hosono \\ Fiona C. Meldrum \\ Kornelius Nielsch \\ Eric A. Stach \\ Stephen K. Streiffer \\ Loucas Tsakalakos
}

\section{Publications Committee}

R.A. Vaia, Chair

S.P. Baker, Editors Subcommittee

A.J. Hurd, New Publication Products Subcommittee

J.M. Phillips, Publications Quality Subcommittee

\section{MRS Committee Chairs}

B.M. Clemens, Academic Affairs

C.B. Carter, Awards

N. Bassim, Government Affairs

D.S. Ginley, Meetings Committee
Y. Chabal, Member Engagement

R.A. Vaia, Publications

A. Risbud, Public Outreach

\section{MRS Headquarters}

T.M. Osman, Executive Director

J.A. Dillen, Director of Finance and Administration

P.A. Hastings, Director of Meeting Activities

E.K. Novak, Director of Communications

\section{Journal of Materials Research Founding Sponsors}

\author{
Allied-Signal Inc.
}

Xerox Corporation

\begin{abstract}
About the Materials Research Society
The Materials Research Society (MRS ${ }^{\circledR}$ ) is a not-for-profit scientific association founded in 1973 to promote interdisciplinary goal-oriented basic research on materials of technological importance. Membership in the Society includes over 16,000 scientists from industrial, government, and university research laboratories in the United States and abroad.

The Society's interdisciplinary approach to the exchange of technical information is qualitatively different from that provided by single-discipline professional societies because it promotes technical exchange across the various fields of science affecting materials development. MRS sponsors three major international annual meetings encompassing many topical symposia, as well as numerous single-topic scientific meetings each year. It recognizes professional and technical excellence, conducts tutorials, and fosters technical exchange in various local geographical regions through Section activities and Student Chapters on university campuses.
\end{abstract}

MRS publishes symposia proceedings, the MRS Bulletin, and other volumes on current scientific developments. The Journal of Materials Research, the archival journal spanning fundamental developments in materials science, is published twenty-four times a year by Cambridge University Press for the MRS. MRS Communications is a full-color letters and prospectives journal focused on groundbreaking work across the spectrum of materials research.

MRS regular and student members may subscribe to Journal of Materials Research. See inside front cover for subscription rates for Journal of Materials Research.

MRS is an Affiliated Society of the American Institute of Physics and participates in the international arena of materials research through associations with professional organizations.

For further information on the Society's activities, contact MRS Headquarters, 506 Keystone Drive, Warrendale, PA 15086-7573; telephone (724) 779-3003; fax (724) 779-8313. 

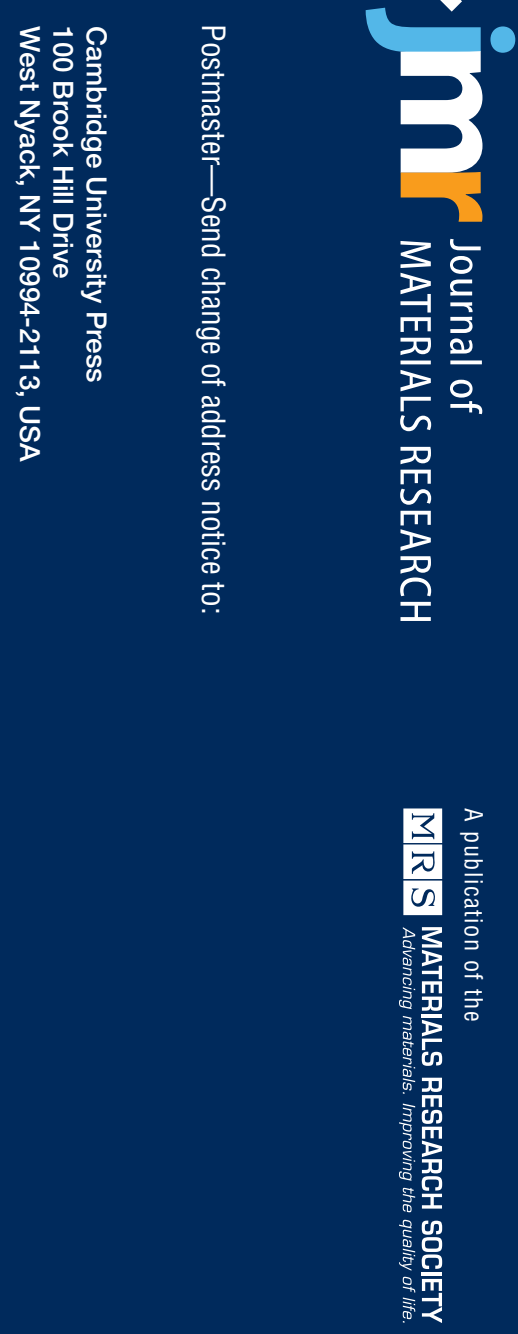

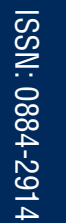

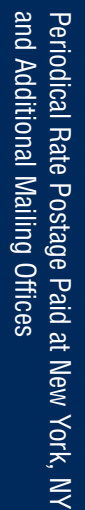

